\title{
Analyses of Microstructural Properties of VA/VeoVA Copolymer Modified Cement Pastes
}

\author{
Carlos Eduardo M. Gomes \\ Interunidades em Ciência e Engenharia de Materiais, USP \\ Osny P. Ferreira \\ Escola de Engenharia de São Carlos, USP
}

\begin{abstract}
Recently, modern techniques have been applied for analysis of the influence of polymers on microstructural properties of Portland cement, such as Thermogravimetric Analyses (TG), Scanning Electronic Microscopy (SEM), Fourier Transform Infrared Spectroscopy (FT-IR) and Mercury Intrusion Porosimetry (MIP). In this study, thermogravimetric analyses were used to study the influence of vinyl acetate-versatic vinylester copolymer (VA/VeoVA) in seven pastes of 28-day old Portland cement, in which distinct polymer contents and water/cement ratios were employed. In addition, analyses of FT-IR and MIP on Portland cement pastes modified by the copolymer were employed. The results showed that the addition of polymer interferes significantly in the reduction of Portlandite formation and increases the porosity of the matrices. A possible chemical interaction between the copolymer and hydrated products of Portland cement was also observed.
\end{abstract}

Keywords: Cement paste, modified mortars, VA/VeoVA copolymer.

\section{Introduction}

The polymer application in Portland cement composites is not new and the concept of polymer modification has been researched for the past 75 years or more. In the last 30 years, several publications have shown the benefit of polymer addition in the properties of the Portland cement composite such as strength, deformability, adhesion, waterproofness and durability ${ }^{[1-3]}$.

There are several kinds of polymeric compounds for applications in concretes such as polymer latex, redispersible polymer powder, water-soluble polymer and liquid polymer ${ }^{[2-4]}$. Because of the easy application ${ }^{[3]}$, the redispersible polymers are commonly used in the composites, such as the poly(ethylene-vinyl acetate) - EVA, poly(styreneacrylic ester) - SAE, the polyacrylic ester - PAE and poly(vinyl acetate-vinyl versatate) - VA/VeoVA.

To understand the interference of polymer modification in the formation of some phases of Portland cement composite, several techniques have been adopted such as scanning electronic microscopy, Fourier transform infrared spectroscopy and the thermogravimetric analysis, which is also used in several studies to determine the amount of the pozzolanic reaction and the hydration of cement pastes by quantifying $\mathrm{Ca}(\mathrm{OH})_{2}$ content and calcium hydrates content.

FT-IR is one of the powerful techniques normally used for molecular characterization. Recently, FT-IR has been found to be very useful in delineating the complex chemistry involved in the hydration of cement. In particular, the FT-IR results have been used to resolve the hydroxyl bands, to understand the degree of silicate polymerization occurring, and to monitor the dynamics of changes in the sulfate region during hydration reaction. Also, the effect of atmospheric carbon dioxide on hydration has been characterized ${ }^{[5]}$.

In this way, this work reports results of investigations in which methods of thermal analysis and FT-IR were applied to evaluate the effects of copolymer modification on the hydration process and the possible interaction between copolymer and Portland cement respectively. In addition, analysis of PIM was also applied.

\section{State-of-art review}

\section{Polymer-Based Admixtures}

The concept of polymer modification is not new and the first patent was obtained in 1923. This patent refers to the use of cement as filler in a polymer matrix. In 1924, the first patent was published using the concept of polymer modification for cement mortar and concrete ${ }^{[2,4,6]}$.

Basically, there are three kinds of polymer-based admixtures also called cement modifiers: polymer-modified mortar (PMM); polymer mortar (PM); and polymerimpregnated mortar (PIM) and concrete (PIC).

The first PIC was produced by impregnating hydrated Portland cement concrete with a low viscosity monomer, such as methyl methacrylate, which was subsequently

Autor para correspondência: Carlos Eduardo M. Gomes, Laboratório de Construção Civil, LCC - USP, Avenida do Trabalhador São-carlense 400, CEP:13560-970, São Carlos, SP. E-mail marmorato@itelefonica.com.br. 
polymerized by radiation or thermal catalytic techniques. However, at present, apparently its use is not very common.

PC consists of aggregate with a polymer binder and contains no Portland cement or water. Polyester-styrene, acrylics and epoxies have been the most widely used monomers/resins, but vinyl ester, furan, and urethane, have also been used.

PMM consists of Portland cement mortar with a polymer modifier such as acrylic or styrene-butadiene latex (SB), polyvinyl acetate, ethylne vinyl acetate, and polyvinyl acetatevinyl versatate (VA/VeoVA).

In general, these polymers for use in the mortars and concretes can be classified into four main types: polymer latex (dispersion), redispersible polymer powder; water-soluble polymer and liquid polymer.

Redispersible polymer powders are manufactured by a twostep process. Firstly, polymer latexes as raw materials are made by emulsion polymerization, and are spray-dried to obtain the polymer-powders. Before spray-drying, the latexes are further formulated with some ingredients such as bactericides, spray-drying aids and antifoaming agents. Anti-blocking aids such as clay silica and calcium carbonate are added to the polymer powders during or after spray-drying to prevent caking of the polymer powders during storage.

Water-soluble polymers as polymer-based admixtures are water-soluble powdered polymers, such as cellulose derivatives, polyvinyl alcohol, polyacrylamide, etc; they are added in the form of powders or aqueous solutions to the cement mortar or concrete during mixing.

Liquid polymers as polymer-based admixtures are viscous polymeric liquids such as epoxy resin and unsaturated polyester resin, and are added with hardener or catalyst, and accelerator to cement mortar or concrete during mixing.

\section{Polymer Modification}

As a principle of polymer modification, it is very important that both Portland cement hydration and polymer film formation proceed well in order to produce a monolithic matrix phase with a network structure in which the cement hydrate phase and polymer phase interpenetrate. The modification with redispersible polymer powders (as the modification with VA/VeoVA used in this study) is similar to that of latex formation except that it also involves the redispersion of polymer powders. In these cases, the modification is governed by both Portland cement hydration and polymer film formation processes in their binding phase. The cement hydration process generally precedes the polymer film formation by coalescence of polymer particles.

\section{Interaction between Polymer and Portland Cement Hydration}

There are two theories for the mechanism of action of polymers in mortars and concretes. According to the first theory there is no interaction between the polymer and concrete. During hydration the hydrophilic part of the polymer is oriented towards the water phase whereas the hydrophobic part heads towards the air phase (pores and capillaries not pilled with water). Upon drying, the water is taken away, the hydrophobic particles coalesce together and form film. The other theory is that some chemical reactions may take place between the particle surfaces of reactive polymers (such as polyacrylic esters (PAE) and calcium ions $\left.\mathrm{Ca}^{2+}\right), \mathrm{Ca}(\mathrm{OH})_{2}$ and solid surfaces or silicate surfaces over the aggregates. This creates a type of reinforcement in the concrete and that will produces semipermeable membranes ${ }^{[1]}$.

\section{The importance of the Thermal Analyses}

Thermal analysis is the term used to identify a group of methods and techniques in which a physical property of a substance is measured as a function of temperature. Thermogravimetry (TG) and derivative thermogravimetry (DTG) have proven to be valuable tool for evaluating the nature of hydration products according to different stages of cement hydration, as well as quantify the different phases ${ }^{[1,6-9]}$.

When cement is hydrated its main components are transformed into hydration products, mainly calcium silicate hydrates (C-S-H gel) and Portlandite. The hydration rate of cement can be evaluated by measuring the mass loss of hydrated compounds up to $800{ }^{\circ} \mathrm{C}$. Some DTG peaks or temperature range have been reported when hydrated cement is heated in thermobalance ${ }^{[7]}$ :

- $100{ }^{\circ} \mathrm{C}$ : dehydration of pore water

- $100-300^{\circ} \mathrm{C}$ : different stages of C-S-H dehydration

- $~ 500{ }^{\circ} \mathrm{C}$ : dehydroxylation of $\mathrm{Ca}(\mathrm{OH})_{2}$

- $\sim 700^{\circ} \mathrm{C}$ : decarbonation of $\mathrm{CaCO}_{3}$

As explained above, polymer modification reduces the quantity of $\mathrm{Ca}(\mathrm{OH})_{2}$ formed in the mortars ${ }^{[10]}$. This work reports results of investigations in which methods of thermal analysis were applied to evaluate the effects of polymer modification on the hydration process of Portland cement by estimating $\mathrm{Ca}(\mathrm{OH})_{2}$ content and calcium hydrates content.

\section{Experimental}

\section{Materials}

The materials employed for paste preparation were highearly-strength Portland cement (CP-V type according to Brazilian standards NBR-5733 and NBR-5737) and redispersible polymer VA/VeoVA. Characteristics of these materials are shown in Tables 1 and 2.

\section{Methods}

The range was formed by four pastes with different polymer content (A-0\%; B- $10 \%$; C-20\% e D- $40 \%$ ) and the same water/cement ratio, and the other three (E-10\%; F-20\% e G-40\%) with extra water content increased by polymer content.

The following procedure was employed for the mixing of pastes: (i) dry mixing of $\mathrm{Va} / \mathrm{Veo} \mathrm{Va}$ and cement in low-speed mechanical mixer; (ii) dry mixing flowing over water plus superplasticizer; (iii) paste mixing in low-speed mechanical mixer for $180 \mathrm{~s}$; (vi) casting in hermetic cylindrical flasks; 
Table 1. Chemical analyses of Portland cement

\begin{tabular}{ccccc}
\hline \multicolumn{5}{c}{ Four chemical analyses of high-early-strength } \\
Portland cement $(\%)$
\end{tabular}

Table 2. Physical characteristics of VA/VeoVA copolymer

\begin{tabular}{cc}
\hline \multicolumn{2}{c}{ Physical analyses } \\
\hline Solids content $(\%)$ & $99 \pm 1$ \\
Anti-blocking content $(\%)$ & $12 \pm 2$ \\
Apparent density $\left(\mathrm{g} / \mathrm{cm}^{3}\right)$ & 0,45 to 0,60 \\
Particle size $(\mu \mathrm{m})$ & $80 \pm 10$ \\
\hline
\end{tabular}

(v) demoulding $24 \mathrm{~h}$ after casting; (vi) dry cure was maintained at $75 \%$ relative humidity (RH) up to 27 days old; (vii) preparation for analyses on $28^{\text {th }}$ day.

The preparation for $T G$ was realized using agate crucible where the paste was triturated until particles size lower than $0,074 \mathrm{~mm}$. The analyses were realized using the thermal analyzer TGA 951. The experimental conditions were: air dynamic atmosphere $(100 \mathrm{ml} / \mathrm{min})$; heating rate $\left(10^{\circ} \mathrm{C} \mathrm{min}^{-1}\right)$; platinum top-opened crucible; and specimens of approximately $7 \mathrm{mg}$.

FT-IR analyses were realized in the BOMEM FT-IR model MB-102 equipment, using $\mathrm{KBr}$ pallets in the proportion $1 \mathrm{mg}$ of specimen: $100 \mathrm{mg}$ of $\mathrm{KBr}$, spectra range of $4000 \mathrm{~cm}^{-1}$ until $300 \mathrm{~cm}^{-1}$ and bands intensities expressed in transmittance $(\% \mathrm{~T})$.

To verify the porosity, the pastes $\mathrm{A}, \mathrm{B}, \mathrm{C}$, and $\mathrm{D}$ were cut with a diamond saw at 28 days old, making cubes of edge equal to $10 \pm 1 \mathrm{~mm}$. Before analyses, the specimens were immersed in iso-propyl alcohol, cleaned by ultrasonic equipment and dried in vacuum for 24 hours. All the analyses were realized in a PoreSizer 9320 equipment.

\section{Results and Discussion}

Table 3 shows the mixture proportions analyzed. Figures 1 and 2 show the thermogravimetric analyses whose results are shown in the Table 4.
Table 3. Mixture proportions

\begin{tabular}{ccccc}
\hline Pastes & Cement & $\begin{array}{c}\text { additional } \\
\text { copolymer } \\
\text { content (\%) }\end{array}$ & $\begin{array}{c}\text { W/C } \\
\text { ratio }\end{array}$ & $\begin{array}{c}\text { water/(copolymer+ } \\
\text { cement) ratio }\end{array}$ \\
\hline A & 1 & 0 & 0,35 & - \\
B & 1 & 10 & 0,35 & - \\
C & 1 & 20 & 0,35 & - \\
D & 1 & 40 & 0,35 & - \\
E & 1 & 10 & - & 0,35 \\
F & 1 & 20 & - & 0,35 \\
G & 1 & 40 & - & 0,35 \\
\hline
\end{tabular}

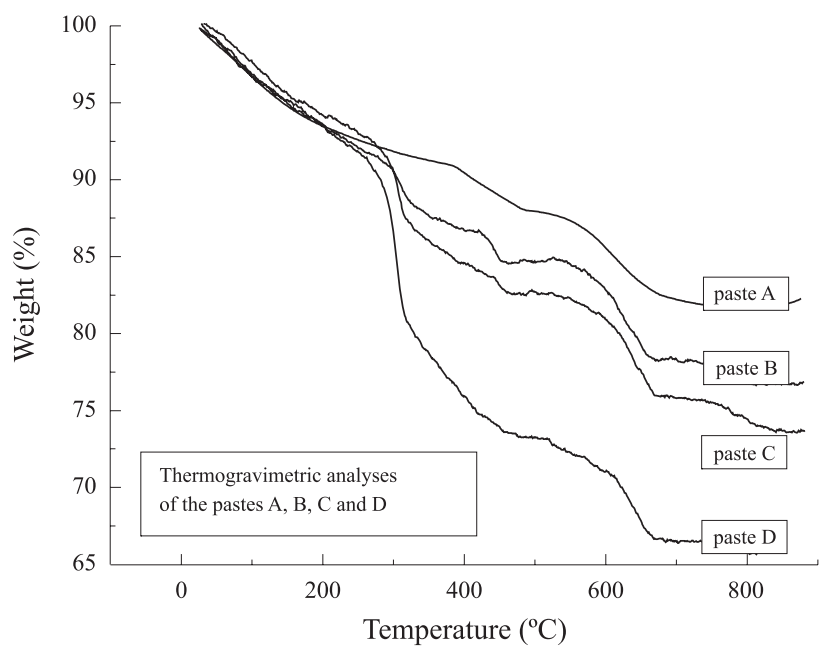

Figure 1. Influence of $\mathrm{Va} / \mathrm{Veo} \mathrm{VA}$ content in the Portland cement paste

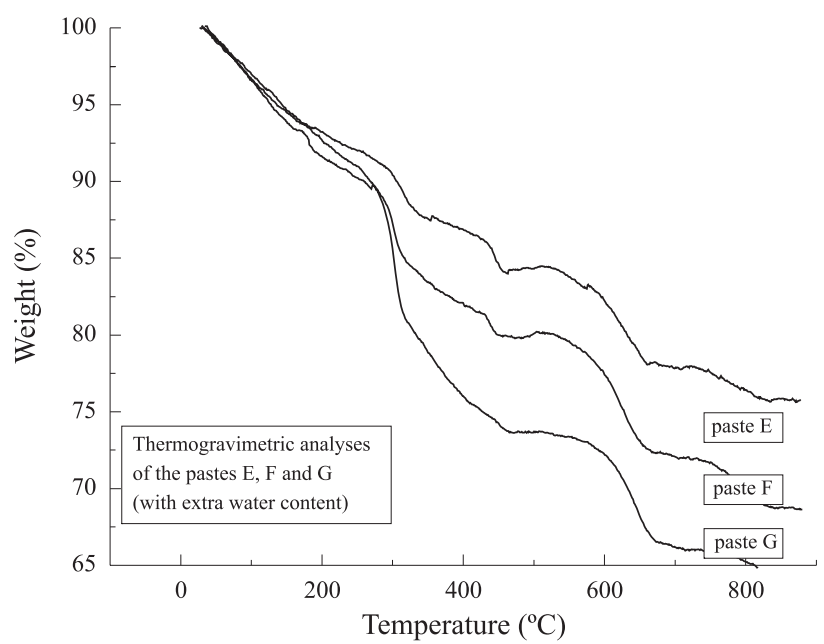

Figure 2. Influence of Va/VeoVA (with extra water content) in the Portland cement paste

Figure 3 and Table 5 show the porosity of the matrices in terms of accumulated volume versus average pore.

As seen in the Figures 1 and 2, the presence of VA/VeoVa copolymer interferes in the behavior of the hydroxide calcium and its content (Table 4). Considering the weight loss in the 
Table 4. Results of the thermogravimetric analyses

\begin{tabular}{|c|c|c|c|c|c|c|}
\hline Mixture & $\begin{array}{l}\text { Dehydration and } \\
\text { decomposition of } \\
\text { the } \mathrm{C}-\mathrm{S}-\mathrm{H}^{*} \\
25^{\circ} \mathrm{C} \sim 200^{\circ} \mathrm{C}\end{array}$ & $\begin{array}{c}\text { Weight loss } \\
\text { from polymer } \\
\text { pyrolysis** } \\
200^{\circ} \mathrm{C} \sim 400^{\circ} \mathrm{C}\end{array}$ & $\begin{array}{c}\text { Decomposition } \\
\text { of the } \mathrm{Ca}(\mathrm{OH})_{2} \\
(\text { Portlandite) } \\
400^{\circ} \mathrm{C} \sim 500^{\circ} \mathrm{C}\end{array}$ & $\begin{array}{l}\text { Decomposition } \\
\text { of the } \mathrm{CaCO}_{3} \\
500{ }^{\circ} \mathrm{C} \sim 750{ }^{\circ} \mathrm{C}\end{array}$ & $\begin{array}{c}\text { Decomposition } \\
\text { of the carbonate } \\
\text { phases } * * * \\
700^{\circ} \mathrm{C} \sim 850{ }^{\circ} \mathrm{C}\end{array}$ & Above $850{ }^{\circ} \mathrm{C}$ \\
\hline A & $6,540 \%$ & $0 \%$ & $2,928 \%$ & $6,423 \%$ & - & $81,56 \%$ \\
\hline B & $8,213 \%$ & $5,077 \%$ & $2,005 \%$ & $6,318 \%$ & $1,545 \%$ & $76,87 \%$ \\
\hline $\mathrm{C}$ & $5,822 \%$ & $9,608 \%$ & $2,075 \%$ & $6,690 \%$ & $2,141 \%$ & $73,67 \%$ \\
\hline D & $4,499 \%$ & $17,81 \%$ & $1,364 \%$ & $6,689 \%$ & - & $65,78 \%$ \\
\hline E & $7,965 \%$ & $4,993 \%$ & $2,642 \%$ & $6,146 \%$ & $2,381 \%$ & $75,67 \%$ \\
\hline $\mathrm{F}$ & $9,107 \%$ & $8,863 \%$ & $1,965 \%$ & $8,119 \%$ & $3,290 \%$ & $68,78 \%$ \\
\hline G & $8,770 \%$ & $15,96 \%$ & $1,650 \%$ & $7,715 \%$ & $1,854 \%$ & $64,07 \%$ \\
\hline
\end{tabular}

*calcium silicate hydrate $\quad * *$ acetate group elimination $* * *$ different crystalline compounds

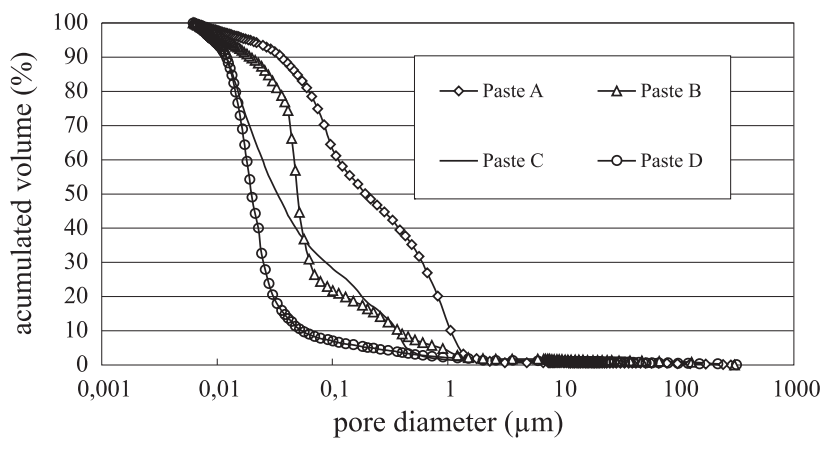

Figure 3. Accumulated volume $(\%)$ versus Pore diameter $(\mu \mathrm{m})$

Table 5. Results of porosimetry

\begin{tabular}{ccccc}
\hline Properties & Paste A & Paste B & Paste C & Paste D \\
\hline $\begin{array}{c}\text { Apparent density } \\
\left(\mathrm{g} / \mathrm{cm}^{3}\right)\end{array}$ & 2.44 & 2.25 & 2.14 & 1.97 \\
Real density $\left(\mathrm{g} / \mathrm{cm}^{3}\right)$ & 1.82 & 1.62 & 1.47 & 1.33 \\
Total porosity $(\%)$ & 25.26 & 28.06 & 31.24 & 32.27 \\
Average pore $(\mu \mathrm{m})$ & 0.0751 & 0.0534 & 0.0258 & 0.0191 \\
\hline
\end{tabular}

graphs it is to be noted that the quantity of $\mathrm{Ca}(\mathrm{OH})_{2}$ is less than that unmodified mortar and it is gradually decreased along with the increase of the polymer content. These results are in line with those shown by the studies of reference 10 , which employed similar proceedings.

The decrease of portlandite formation by addition of the cement modifiers can be both the consequence of lower cement hydration and a possible chemical interaction between groups from alkaline hydrolyses of polymers and hydration products of portland cement ${ }^{[1,9,10]}$. As shown in reference ${ }^{[13]}$, some polymers that contain vinyl acetate group can suffer hydrolysis when dispersed in alkaline medium. The product of this hydrolysis is the acetate anion $\left(\mathrm{CH}_{3} \mathrm{COO}\right)^{-}$, which can react with $\mathrm{Ca}++$ ion from $\mathrm{C}_{2} \mathrm{~S}$ and $\mathrm{C}_{3} \mathrm{~S}$ hydration and form an organic salt (calcium acetate). Some evidence of this chemical interaction is also detailed in FT-IR analyses.

In this way, the decrease of portlandite formation in the cement pastes can also be attributed to chemical interaction between VA/VeoVA and cement paste.

The formation of calcium acetate increases the loss weight of the carbonate phases as shown below:

$$
\begin{array}{ccc}
\mathrm{Ca}\left(\mathrm{CH}_{3} \mathrm{COO}\right)_{2}(\mathrm{~s}) \stackrel{\left(\sim 380^{\circ} \mathrm{C} \text { to } 400^{\circ} \mathrm{C}\right)}{\longrightarrow} & \mathrm{CH}_{3} \mathrm{COCH}_{3}(\mathrm{~g})+\mathrm{CaCO}_{3}(\mathrm{~s}) \\
\text { calcium acetate } & \text { acetone } & \begin{array}{l}
\text { calcium } \\
\text { carbonate }
\end{array}
\end{array}
$$

This was not clearly observed in the results because of specimens carbonation and the lower degeneration of VeoVA based copolymers in alkaline environment.

Some polymers may reduce the hydration at early ages, in this way, the reduction of calcium hydroxide appears to be more related to lower cement hydration. As previously illustred, the analyses of pastes E, F and G with extra water content showed a major quantity of $\mathrm{Ca}(\mathrm{OH})_{2}$ when compared with pastes $\mathrm{B}, \mathrm{C}$ and $\mathrm{D}$ respectively.

It is evident that the addition of the cement modifier reduces the calcium hydroxide formation and interferes in other important phases. However, the magnitude of this influence and reduction in the quantity of $\mathrm{Ca}(\mathrm{OH})_{2}$ showed to be directly affected by the polymer/cement and water/ cement ratio. Moreover, it is possible the reduction of portlandite by its reaction with the $\mathrm{CO}_{2}$ from the polymer oxidation during TG analysis is possible.

Regardless the presence of VA/VeoVA in the pastes, the following bands it could be observed on the FT-IR spectrum: calcium hydroxide bands $\left(3642 \mathrm{~cm}^{-1}\right)$, combined and absorbed water of C-S-H, Afm, and Aft, phases (3440-3446 $\mathrm{cm}^{-1}$ ), molecular water (3440-3446 and 1640-1645 $\left.\mathrm{cm}^{-1}\right)$, carbonate phases (1424-1436, 874-880 and 704-712 $\mathrm{cm}^{-1}$ ), sulphates phases (1116-1118 $\left.\mathrm{cm}^{-1}\right)$, anhydrous calcium silicates $(920$, $526-536$ and $\left.458-464 \mathrm{~cm}^{-1}\right)$ and calcium silicates $\left(970-986 \mathrm{~cm}^{-1}\right)$. 




Figure 4. FT-IR spectrums of pastes A, B, C and D $(w / c=0.35)$

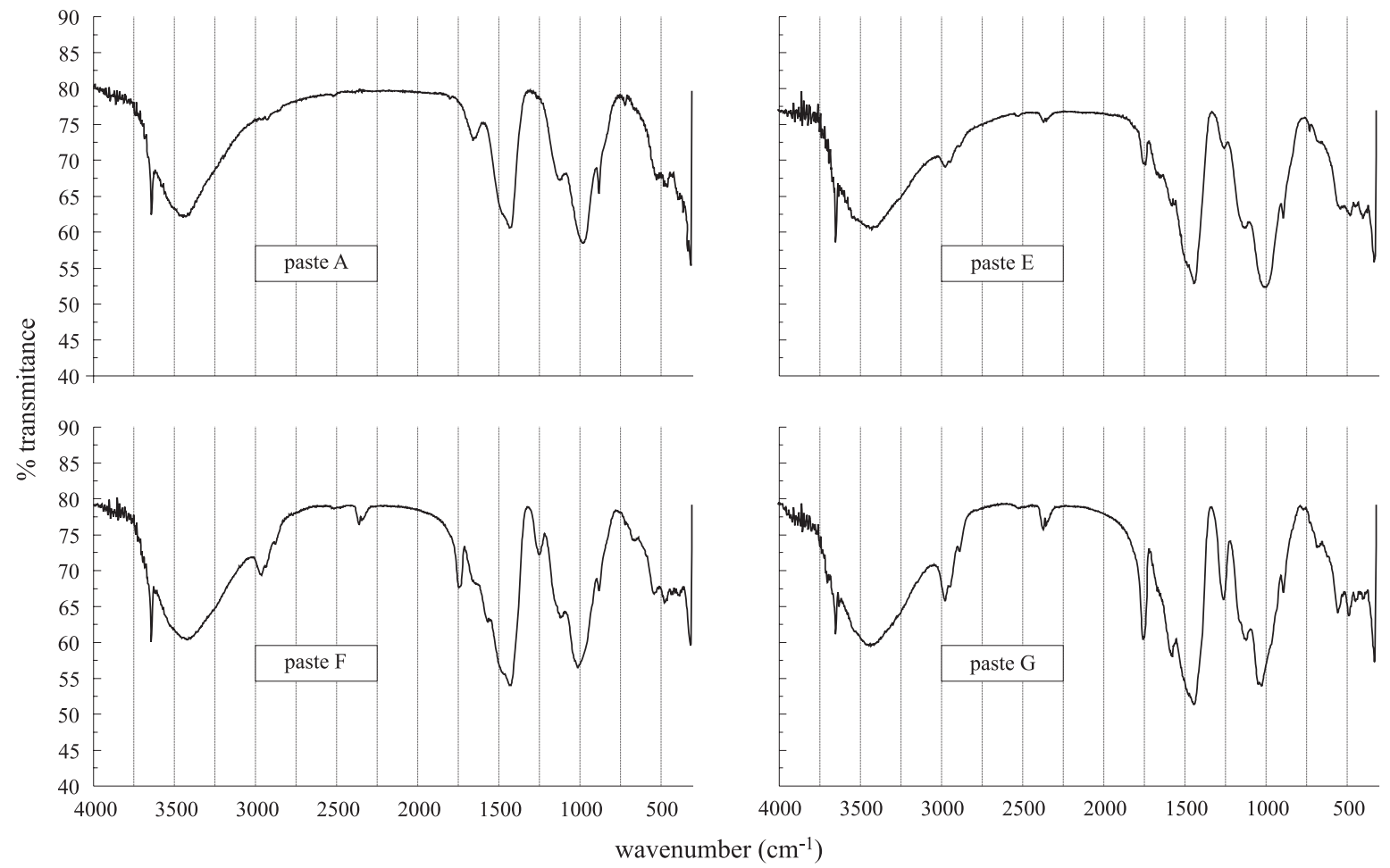

Figure 5. FT-IR spectrums of pastes A, E, F and G $(w /(c+c o p)=0.35$.

Although in the spectrums of Figures 4 and 5 it was possible to observe the infrared bands at $\left(1558-1568 \mathrm{~cm}^{-1}\right)$, which are characteristics of carboxylate anion from partial hydrolysis of the vinyl acetate group, as previously written, the loss weight was not significant in the TG analyses and it could not be measured. These results were attributed to lower degeneration of VeoVA based copolymers in an alkaline environment rather than other copolymers that contain the vinyl acetate group.

The porosimetry analyses showed that the addition of VA/ VeoVA increase the porosity of the matrices substantially. These results are due to the air incorporated during the mixing process. Although the use of copolymer increased the air 
incorporated content, there was a reduction of the average pore diameter in the matrices.

\section{Conclusions}

The TG curves obtained showed typical aspects of the Portland cement mortar modified by polymer.

All curves showed the phenomena of the vaporization of the free water and decomposition of C-S-H from about $25^{\circ} \mathrm{C}$ to $200{ }^{\circ} \mathrm{C}$. The weight loss between $400{ }^{\circ} \mathrm{C}$ and $500{ }^{\circ} \mathrm{C}$ are due to the decomposition of Portlandite. The decomposition of carbonate phases had occurred at about $500^{\circ} \mathrm{C}$ and $850{ }^{\circ} \mathrm{C}$, being the phenomena of this enlargement attributed to weight loss of different crystalline compounds.

VA/VeoVA copolymer does not cause important modifications in the spectral profile of modified pastes, except for the possible interaction between copolymer and portland cement. These results were attributed to lower degeneration of VeoVA based copolymers in an alkaline environment rather than other copolymers that contain the vinyl acetate group.

The addition of VA/VeoVA copolymer strongly reduces the Portlandite formation, being this result attributed principally to lower Portland cement hydration.

Concerning porosimetry, it was observed that the air incorpored content of modified pastes is higher than the one in unmodified pastes. The lowest average pore diameter was also observed for modified pastes. Due to lower density of VA/VeoVA copolymer, the pastes showed a decrease of the real and apparent density in comparison with unmodified mortars.

\section{Acknowledgments}

The authors acknowledge the support of Rhodia Group, The Institute of Chemistry of São Carlos and The Institute of Physics of São Carlos, University of São Paulo, where the analyses were carried out.

\section{References}

1. Chandra, S \& Flodin, P. - Cement Concrete Research, vol.17, p.975-890 (1990).

2. Ohama, Y. - Concrete Composites, vol.20, p.189-212 (1998).

3. Ohama, Y. - Advn. Cement Bas. Materials, v.5, p.31-40 (1997).

4. Fowler, D. W. - Cement and Concrete Composites, vol.21, p.449-452 (1999).

5. Mollah, M. Y. A. et al. - Cement and Concrete Research, vol. 30, pp.267-273 (2000).

6. Dweck, J. et al. - Thermochimica Acta 346, p. 105-113 (2000).

7. Fordham, C. J.; Smalley, I. J. - Cement and concrete research, vol. 15, p. 141-144 (1985).

8. Ollitrault-Fichet, R. et al. - Cement and Concrete Research, vol 28, n12, pp. 1687-1693 (1998).

9. Tisivilis, S. et al. Journal of thermal analysis, vol. 52, p. 863-870 (1998).

10. Afrid et al. - International Journal of Cement Composites and Lightweight Concrete, vol. 11, n.4, p.235-244 (1989).

11. Kriegel, R. et al. - Proceedings of the $11^{\text {th }}$ International Congress on the Chemistry of Cement (ICCC), pp.171180 (2003).

12. Fordham, C. J.; Smalley, I. J. Cement and concrete research, vol. 15, p. 141-144 (1985).

13. Silva, D. A. et al. - Cement and Concrete Research, vol.2079, pp.1-8 (2002).

Enviado: $31 / 08 / 04$

Reenviado: 04/02/05

Aprovado: 10/03/05 